\title{
Synchronous ipsilateral carcinoma of the accessory mammary gland and primary lymphoma of the breast with subsequent rectal carcinoma: report of a case
}

\author{
Akihiro Nishikawa ${ }^{1}$, Hide Kasai ${ }^{1}$, Yoshinori Koyama ${ }^{1}$, Naohiko Koide $^{1 *}$, Akihiro lijima², Hisashi Shimojo ${ }^{3}$ \\ and Shigeyoshi Kumeda ${ }^{1}$
}

\begin{abstract}
A case of synchronous carcinoma of the accessory mammary gland and primary breast lymphoma with subsequent rectal carcinoma has not been reported previously. We present a very rare case of primary non-Hodgkin lymphoma of the left breast diagnosed simultaneously with invasive lobular carcinoma of the left axillary accessory mammary gland and rectal adenocarcinoma. An 82-year-old Japanese woman presented with two palpable masses on the left chest wall. She was given a diagnosis of suspected breast malignant tumor and axillary accessory mammary gland. She underwent excision of the axillary accessory mammary gland and left mastectomy with axillary lymph node dissection. Histopathological examination revealed diffuse large B-cell lymphoma of the breast and invasive lobular carcinoma of the axillary accessory mammary gland with lymph nodes metastasis. Three months after the surgery, primary rectal adenocarcinoma was also detected by F-18 fluorodeoxyglucose positron emission tomography. Hartmann's operation was performed, since which time the patient has been doing well.
\end{abstract}

Keywords: Synchronous malignancy, Accessory mammary gland, Breast carcinoma, Primary breast lymphoma, Rectal carcinoma, Diffuse large B-cell lymphoma, Invasive lobular carcinoma

\section{Background}

The synchronous occurrence of multiple neoplastic processes is uncommon, and coexistence with cancer and lymphoproliferative diseases of the breast is also unusual [1]. Furthermore, a carcinoma arising in the accessory mammary gland is rare, especially of the invasive lobular type [2]. We present an extremely rare case of synchronous primary non-Hodgkin lymphoma (NHL) of the left breast with invasive lobular carcinoma of the ipsilateral axillary accessory mammary gland, with subsequent rectal adenocarcinoma.

\section{Case presentation}

An 82-year-old Japanese woman was referred to our hospital with two left breast masses. She had no previous

\footnotetext{
* Correspondence: nkoide@shinshu-u.ac.jp

'Department of Surgery, Nagano Prefectural Kiso Hospital, 6613-4,

Fukushima, Kiso 397-8555, Japan

Full list of author information is available at the end of the article
}

breast problems or a family history of breast cancer. She had a history of persistent hepatitis $\mathrm{C}$ virus (HCV) infection, Alzheimer-type dementia, and left femoral neck fracture. No previous fever, night sweats, or weight loss was reported.

Physical examination revealed two masses on the left chest wall. One was a $3 \times 3 \mathrm{~cm}$, firm, freely mobile, and indolent mass in the upper outer quadrant of the left breast. The other was a $2 \times 1 \mathrm{~cm}$, elastic, and freely mobile mass in the lower part of the left axilla. The axillary mass was completely separate from the breast. Laboratory studies showed an increased soluble interleukin-2 receptor level of $547 \mathrm{U} / \mathrm{ml}$, carcinoembryonic antigen of $5.4 \mathrm{ng} / \mathrm{ml}$, and antibody to HCV (anti-HCV) with signalto-cut-off ratio of 12.77. Mammography demonstrated a round, high-density, circumscribed mass, without microcalcification and spicula. Ultrasonographic examination of the breast tumor revealed an oval, hypoechoic, heterogeneous lesion, without posterior acoustic phenomena. Since 
fine-needle aspiration cytology of the breast tumor revealed that it could be categorized as being suspected of malignancy, left mastectomy with axillary lymph node dissection and excision of the axillary accessory mammary gland were performed.
Gross examination of the breast mass revealed a white, firm tumor measuring $2.5 \times 1.5 \mathrm{~cm}$. Microscopic examination revealed diffuse sheet-like proliferation of atypical lymphocytes (Figure 1). The neoplastic cells were large with irregular nuclei containing prominent nucleoli

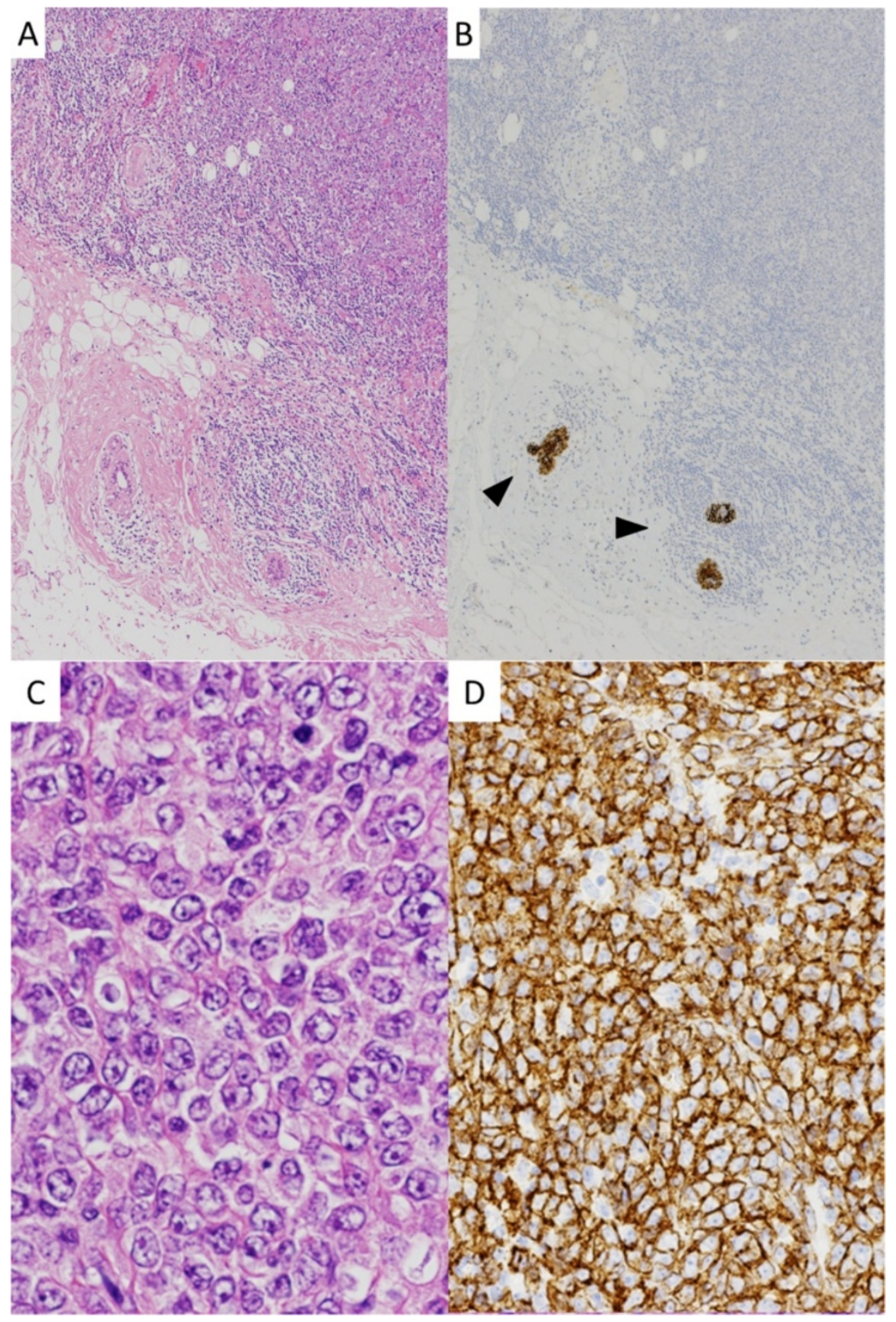

Figure 1 Microscopic examination of the breast tumor. (A) Atypical lymphoid cells have infiltrated diffusely into the mammary glands (hematoxylin and eosin stain, original magnification $\times 4$ ). (B) Cytokeratin stain enhances mammary ducts (arrowheads) (cytokeratin AE1/AE3 immunostain, original magnification $\times 4$ ). (C) The neoplastic cells have a large nucleus containing prominent nucleoli and vesicular chromatin (hematoxylin and eosin stain, original magnification $\times 40)$. (D) The cells are positive for CD20 (CD20 immunostain, original magnification $\times 20)$. 
and vesicular chromatin. Numerous mitotic figures were identified. On immunohistochemistry, the neoplastic cells were positive for CD20 and MUM1, and negative for CD3, CD5, CD10, and Bcl-6. These results confirmed the diagnosis of diffuse large B-cell lymphoma (DLBCL), not otherwise specified, and non-germinal center B-celllike type. On the other hand, histopathology of the axillary tumor revealed ductal structures, fibrous tissue, fat tissue, and infiltrating cancer cells (Figure 2). The cancer cells showed dispersed or trabecular infiltrating growth

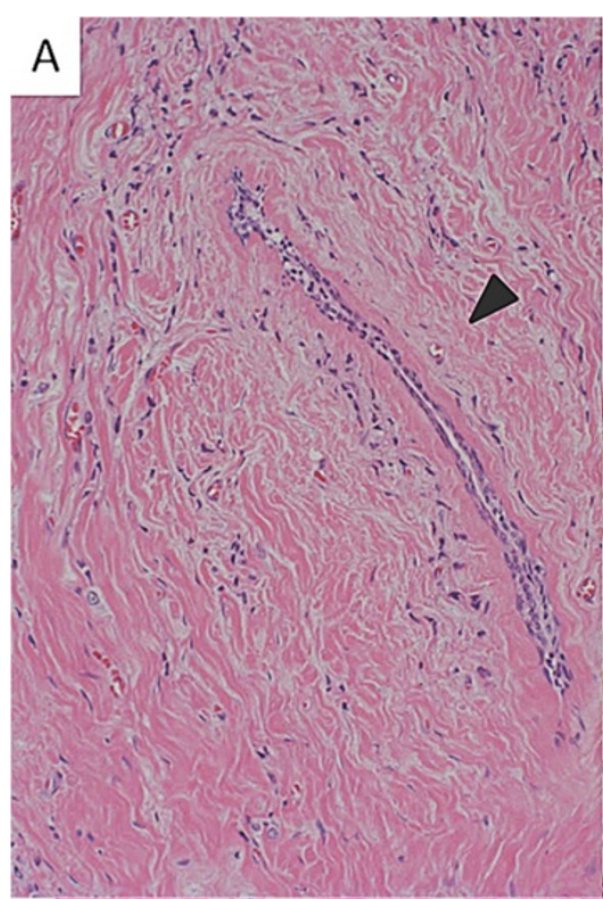

\section{$B$}
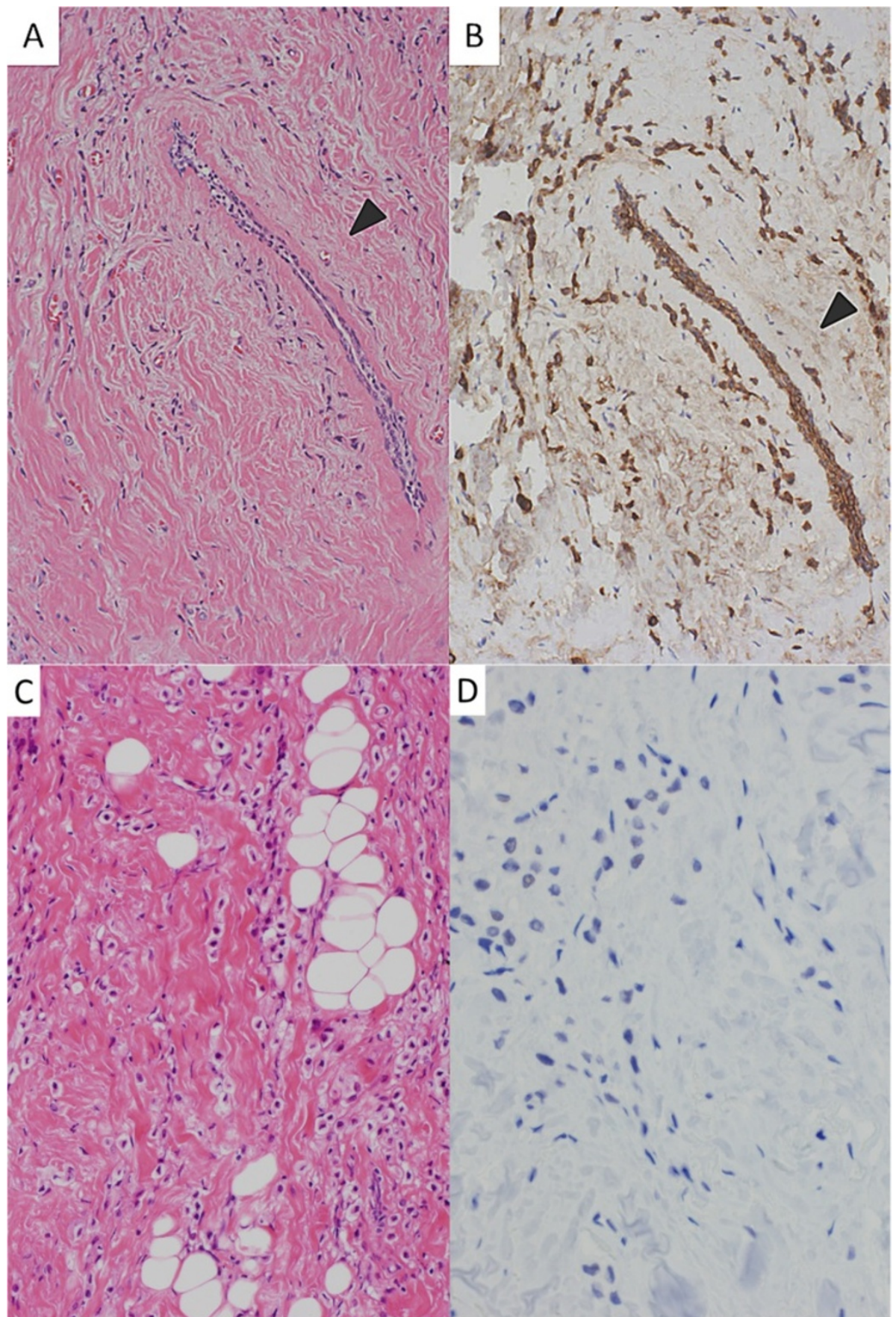

Figure 2 Microscopic examination of the accessory mammary gland. (A) The cancer cells have infiltrated around a mammary duct (arrowhead) (hematoxylin and eosin stain, original magnification $\times 10$ ). (B) Cytokeratin stain enhances the cancer cells and the mammary duct. The mammary duct is adjacent to the cancer cells (arrowhead) (cytokeratin AE1/AE3 immunostain, original magnification $\times 10$ ). (C) The cancer cells have pale to slightly eosinophilic cytoplasm and a nucleus with pale chromatin (hematoxylin and eosin stain, original magnification $\times 20$ ). (D) The cancer cells are negative for E-cadherin (E-cadherin immunostain, original magnification $\times 20$ ). 
in the fibrous tissue and the fat tissue. The cancer cells consisted of pale to slightly eosinophilic cytoplasm and a round nucleus with pale chromatin. On immunohistochemistry, the cancer cells were positive for cytokeratin AE1/AE3 and negative for E-cadherin. Furthermore, they exhibited a positive reaction to anti-estrogen receptor and anti-progesterone receptor, but were negative for HER2. These findings were consistent with invasive lobular carcinoma. All dissected lymph nodes were positive for metastatic lobular carcinoma.

The patient underwent only adjuvant hormonal therapy with anastrozole at a dose of $0.79 \mathrm{mg} / \mathrm{m}^{2} /$ day. F-18 fluorodeoxyglucose positron emission tomography 3 months after the surgery showed no evidence of distant metastasis of the carcinoma or infiltration of the lymphoma; however, it revealed focal accumulation in the lower rectum. Colonoscopy demonstrated a rectal carcinoma forming a fungating tumor with central ulceration. Hartmann's operation was performed. The pathological findings revealed well- to moderately differentiated adenocarcinoma invading through the muscularis propria (Figure 3). There has been no recurrence or distant metastasis in the 7 months of follow-up since the last surgery.

\section{Discussion}

Primary breast lymphoma (PBL) is a rare disease, accounting for $0.05 \%$ to $0.53 \%$ of all malignant breast tumors, $0.38 \%$ to $0.7 \%$ of all lymphomas, and $1.7 \%$ to $2.2 \%$ of all extranodal lymphomas [3-5]. The majority of cases are NHL and the most common histological subtype is DLBCL (40\% to $70 \%$ of all PBLs) [6]. Extranodal marginal zone lymphoma of mucosa-associated lymphoid tissue (MALT lymphoma) is a distinct subgroup of PBL, accounting for $8.5 \%$ to $35 \%$ of all PBLs [6]. The diagnostic criteria for PBL proposed by Wiseman are the standard definition for this disease [7]. These criteria are: 1) presence of technically adequate pathologic specimens, 2) close association of mammary tissue and lymphomatous infiltrate, 3) no prior diagnosis of an extramammary lymphoma, and 4) no evidence of concurrent widespread disease, except for ipsilateral axillary lymph nodes if concomitant with the primary lesion.

The incidence of accessory mammary gland ranges from $0.6 \%$ to $6 \%$ of women in various ethnic groups [8]. Accessory mammary gland tissue is vulnerable to the same physiological and pathological changes, both benign and malignant, as normal breast tissue [9]. Cancer of the accessory mammary gland is a rare entity, accounting for $0.3 \%$ to $0.6 \%$ of all breast cancer [8]. The incidence of malignant change in the accessory mammary gland is unclear because the true incidence of accessory mammary gland is uncertain. The principal malignancy identified in accessory mammary gland is invasive ductal carcinoma (IDC) (79\%), followed by medullary and lobular carcinomas, which are seen in less than $10 \%$ of cases [2]. Mitsuyoshi and colleagues

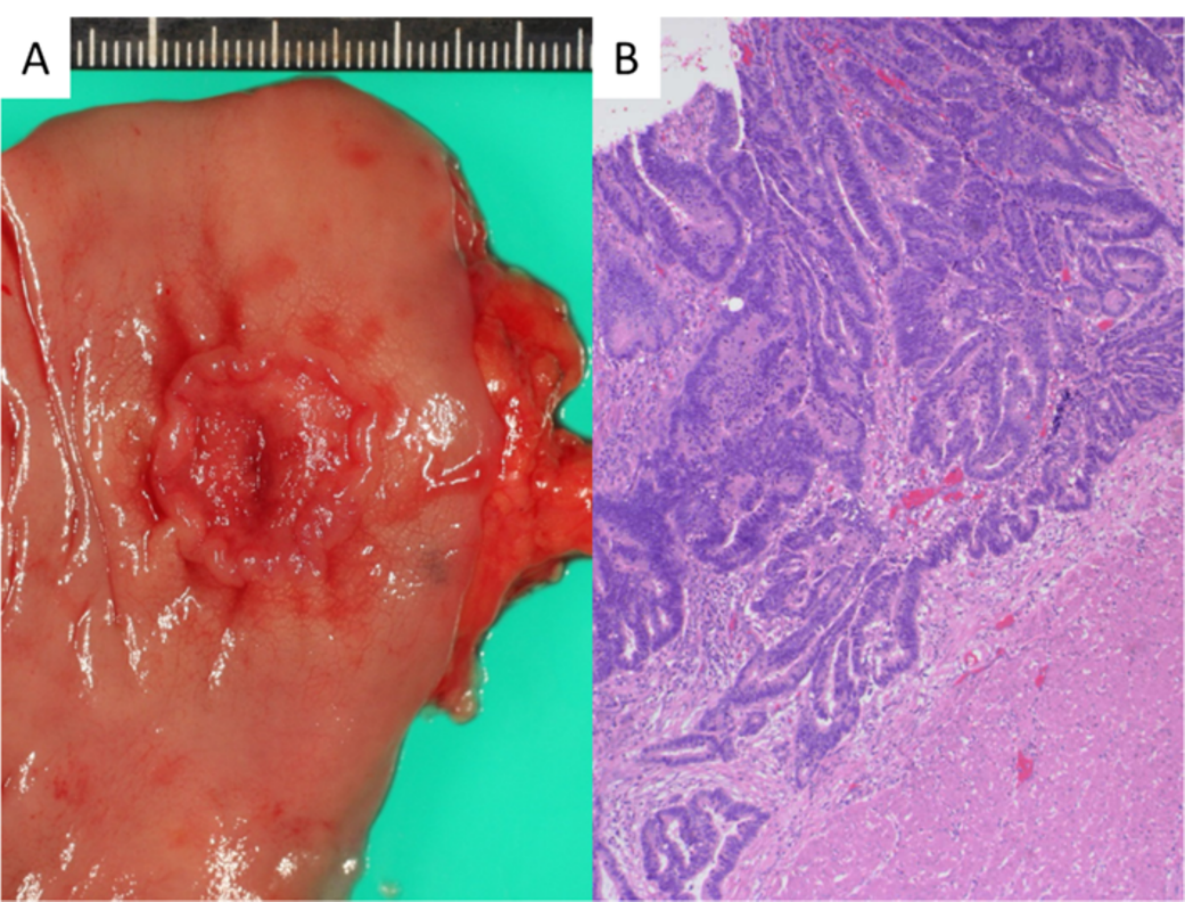

Figure 3 Surgical specimen and microscopic examination of the rectal carcinoma. (A) Surgical specimen showing that is a type 2 tumor measuring $15 \times 15 \mathrm{~mm}$. (B) Microscopic examination shows an adenocarcinoma forms moderate- to large-sized atypical glands. The carcinoma shows infiltrating growth in the muscularis propria (hematoxylin and eosin stain, original magnification $\times 4$ ). 
Table 1 Clinical characteristics of reported cases of synchronous primary breast lymphoma and breast carcinoma

\begin{tabular}{|c|c|c|c|c|c|c|c|c|}
\hline $\begin{array}{l}\text { Case number } \\
\text { [Reference] }\end{array}$ & $\begin{array}{l}\text { Age/ } \\
\text { sex }\end{array}$ & Histology of PBL & $\begin{array}{l}\text { Site of } \\
\text { PBL }\end{array}$ & $\begin{array}{l}\text { Histology of } \\
\text { carcinoma }\end{array}$ & $\begin{array}{l}\text { Size of PBL/carcinoma } \\
(\mathrm{mm})\end{array}$ & $\begin{array}{l}\text { Lymph node } \\
\text { metastasis }\end{array}$ & $\begin{array}{l}\text { Relationship between PBL and } \\
\text { carcinoma }\end{array}$ & Remarks \\
\hline $1[11]$ & $49 / F$ & Diffuse, mixed cell type, B-cell type & Left & IDC & $\begin{array}{c}50 \times 45 / \text { unknown (not } \\
\text { palpable) }\end{array}$ & Absent & Contralateral & - \\
\hline $2[1]$ & $62 / F$ & B-cell NHL, diffuse high grade & Right & IDC & $28 / 9$ & Absent & Contralateral & * \\
\hline $3[12]$ & $62 / F$ & DLBCL & Right & IDC & $29 \times 28 / 13 \times 10$ & Absent & Ipsilateral & - \\
\hline $4[13]$ & $53 / F$ & MALT lymphoma & Left & IDC & $25 / 25$ & PBL & $\begin{array}{c}\text { Ipsilateral, colliding with each } \\
\text { other }\end{array}$ & - \\
\hline $5[14]$ & $57 / F$ & MALT lymphoma & Right & $\mathrm{IDC}+\mathrm{DCIS}$ & $\begin{array}{c}\text { Unknown (palpable)/8 right } \\
+12 \text { left }\end{array}$ & PBL & $\begin{array}{l}\text { Ipsilateral, both in the same } \\
\text { quadrant }\end{array}$ & - \\
\hline $6[15]$ & $47 / F$ & B-cell NHL & Right & IDC & $50 \times 40 \times 40 / 50 \times 40 \times 40$ & Absent & Ipsilateral, adjacent to each other & - \\
\hline $7[16]$ & $79 / F$ & $\begin{array}{l}\text { Large B-cell lymphoma of follicular } \\
\text { cell origin }\end{array}$ & Bilateral & IDC & Both unknown (palpable) & Absent & Ipsilateral distance: $9 \mathrm{~mm}$ & $\dagger$ \\
\hline $8[17]$ & $66 / F$ & DLBCL & Right & DCIS & 20/unknown (palpable) & Absent & Ipsilateral distance: within $2 \mathrm{~cm}$ & - \\
\hline Present case & $82 / F$ & DLBCL & Left & ILC & $25 \times 15 / 17 \times 7$ & Carcinoma & Ipsilateral & $\neq$ \\
\hline
\end{tabular}

*Synchronous triple tumors, with bilateral Brenner tumors of the ovary. +Mouse mammary tumor virus sequences were identified. ₹The carcinoma occurred from the accessory mammary gland and posterior rectal cancer was diagnosed. DCIS, ductal carcinoma in situ; DLBCL, diffuse large B-cell lymphoma; F, female; IDC, invasive ductal carcinoma; ILC, invasive lobular carcinoma; MALT, mucosa-associated lymphoid tissue; NHL, non-Hodgkin lymphoma; PBL, primary breast lymphoma. 
advocated that cancer of the accessory mammary gland must be pathologically demonstrated to be adjacent to normal breast parenchyma that is not connected with normally positioned breast, and it is also necessary to rule out the possibility of a metastatic lesion from another primary cancer [10].

The synchronous occurrence of a carcinoma of the accessory mammary gland and PBL is an extremely rare finding, especially with a rectal carcinoma. To the best of our knowledge, this combination of synchronous double primary malignancies and rectal carcinoma has not been reported previously. We believe that this is the first reported case of its kind.

There have been only eight cases of the coincidence of breast cancer and PBL (excluding cases that did not satisfy Wiseman's criteria for PBL, such as those with bone marrow infiltration); therefore, these are also rare entities [1,11-17]. Herein, we summarize reported cases of synchronous double malignancies, along with our case (Table 1). The ages of the patients varied from 47 to 82 years of age, and the mean age was 61.9 years. Histology of PBL was B-cell NHL in all cases, and the major histological subtype was DLBCL (three cases). The majority of carcinomas were IDC, and only our case was invasive lobular carcinoma. Two neoplasms occurred ipsilaterally in seven cases, and in four cases the two tumors were close, within $2 \mathrm{~cm}$ of each other. In particular, in Case 4, the two tumors were invading each other and presenting as a "collision tumor". Both Susnik and colleagues [18] and Anavekar and colleagues [19] reported cases of concurrent breast MALT lymphoma with bone marrow infiltration and ipsilateral breast cancer, respectively. Interestingly, the case of Susnik and colleagues exhibited a collision tumor like Case 4. In cases with the coincidence of primary or secondary breast lymphoma and breast cancer, MALT lymphoma may occur more frequently than expected.

In Case 7, mouse mammary tumor virus (MMTV) sequences were detected by PCR of samples taken from IDC. MMTV has long been postulated as a causative agent of human breast cancer [20]. However, this remains controversial $[20,21]$. Salmons and Gunzburg reviewed some recent reports in 2013 [21], and they did not accept the association with MMTV and human breast cancer, but suggested that it could be worthwhile to revisit these earlier studies. We did not attempt to detect MMTV sequences in our case.

There is also a possibility that $\mathrm{HCV}$ has been associated with B-lymphocyte proliferative disorders as well as various extrahepatic diseases [22]. On the strength of epidemiological data, emerging biological investigations, and clinical observations, Viswanatha and Dogan summarized and concluded that HCV was involved in the pathogenesis of at least a proportion of patients with
NHL [23]. Okan and colleagues found that the antiHCV seropositivity rate was significantly higher in the DLBCL subgroup ( 4 of 67 cases) than in the controls (9 of 802 cases) [24]. In our case, anti-HCV was examined four times in 1 year before and after admission, and all of the signal-to-cut-off ratios were about 10 and consistently high. This result suggests that the patient had had $\mathrm{HCV}$ infection before admission. There was a non-zero possibility that persistent $\mathrm{HCV}$ infection led to occurrence of the lymphoma.

Susnik and colleagues suggested that the coexistent carcinoma acted as an antigenic stimulant, which may have triggered the lymphomagenesis, a mechanism similar to the pathogenesis of acquired MALT lymphoma of the stomach as a result of the reaction to infection with Helicobacter pylori [18]. Since breast lymphoma usually grows rapidly [25], this suggestion is reasonable. By contrast, Broco and colleagues reported that ipsilateral IDC developed 1 year after an excision biopsy and conservative therapy of PBL, so prior lymphoma might also contribute to carcinogenesis [26]. From the above findings, both prior breast cancer and lymphoma may be possible causes of synchronous malignancy.

\section{Conclusion}

We report an extremely rare case of synchronous ipsilateral carcinoma of the accessory mammary gland and PBL, with subsequent rectal carcinoma.

\section{Consent}

Written informed consent was obtained from the patient for publication of this case report and any accompanying images. A copy of the written consent is available for review by the Editor-in-Chief of this journal.

\section{Abbreviations}

anti-HCV: antibody to hepatitis C virus; DLBCL: diffuse large B-cell lymphoma; HCV: hepatitis C virus; IDC: invasive ductal carcinoma; MALT: mucosaassociated lymphoid tissue; MMTV: mouse mammary tumor virus; NHL: nonHodgkin lymphoma; PBL: primary breast lymphoma; PCR: polymerase chain reaction.

\section{Competing interests}

The authors declare that they have no competing interests.

\section{Authors' contributions}

AN wrote the manuscript. AN, HK, YK, NK, and SK performed the surgery. Al made treatment strategy for HCV infection. HS carried out the pathological examination. All authors approved the final manuscript.

\section{Acknowledgements}

No financial support was required.

\section{Author details}

${ }^{1}$ Department of Surgery, Nagano Prefectural Kiso Hospital, 6613-4, Fukushima, Kiso 397-8555, Japan. ²Department of Gastroenterology, Nagano Prefectural Kiso Hospital, 6613-4, Fukushima, Kiso 397-8555, Japan. ${ }^{3}$ Department of Pathology, Shinshu University School of Medicine, 3-1-1, Asahi, Matsumoto 390-8621, Japan. 
Received: 24 March 2014 Accepted: 2 September 2014

Published: 14 September 2014

\section{References}

1. Frei KA, Bonel HM, Forrer P, Alleman J, Steiner RA: Primary breast lymphoma, contralateral breast cancer, and bilateral Brenner tumors of the ovary. Obstet Gynecol 2002, 100:1079-1082.

2. Marshall MB, Moynihan JJ, Frost A, Evans SR: Ectopic breast cancer: case report and literature review. Surg Oncol 1994, 3:295-304

3. Lamovec J, Jancar J: Primary malignant lymphoma of the breast: lymphoma of the mucosa-associated lymphoid tissue. Cancer 1987, 60:3033-3041.

4. Babovic N, Jelic S, Jovanovic V: Primary non-Hodgkin lymphoma of the breast: is it possible to avoid mastectomy? J Exp Clin Cancer Res 2000, 19:149-154.

5. Topalovski M, Crisan D, Mattson JC: Lymphoma of the breast: a clinicopathologic study of primary and secondary cases. Arch Pathol Lab Med 1999, 123:1208-1218.

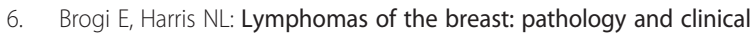
behavior. Semin Oncol 1999, 26:357-364.

7. Wiseman C, Liao KT: Primary lymphoma of the breast. Cancer 1972 29:1705-1712.

8. Teke Z, Kabay B, Akbulut M, Erdem E: Primary infiltrating ductal carcinoma arising in aberrant breast tissue of the axilla: a rare entity. Report of a case. Tumori 2008, 94:577-583.

9. Yerra $L$, Karunad $A B$, Votaw ML: Primary breast cancer in aberrant breast tissue in the axilla. South Med J 1997, 90:661-662.

10. Mitsuyoshi A, Miyoshi K, Nakayama M: [A case of axillary accessory breast cancer and review of reported cases in Japan]. Journal of Clinical Surgery 1990, 45:1289-1293.

11. Kamada H, Aragaki M, Hosokawa Y, Matsuki Y, Komatsu K: A case of both primary simultaneity sides mammary gland malignant tumor (left malignant lymphoma and right mammary cancer). Japanese J Breast Cancer 1998, 13:741-742

12. Hashimoto $M$, Endo $W$, Yokota $K$, Otomo H, Itakura $Y$, Kijima J, Ito $Y$, Nakagawa T, Yoshioka I, Hagiwara M, Nakura H: [Primary breast malignant lymphoma with breast cancer, report of a case]. Kesennuma J Med 2003, 6:47-50.

13. Quilon JM, Gaskin TA, Ludwig AS, Alley C: Collision tumor: invasive ductal carcinoma in association with mucosa-associated lymphoid tissue (MALT) lymphoma in the same breast. South Med J 2006, 99:164-167.

14. Garg NK, Bagul NB, Rubin G, Shah EF: Primary lymphoma of the breast involving both axillae with bilateral breast carcinoma. World J Surg Oncol 2008, 6:52

15. Siddiqui FA, Maheshwari V, Alam K, Jain A: Coexistent non-Hodgkins lymphoma and ductal carcinoma breast: diagnosis on fine needle aspiration cytology. Diagn Cytopathol 2011, 39:767-769.

16. Arlen M, Freiman JJ, lonescu M: Infiltrating ductal carcinoma of the breast associated with primary breast lymphoma. J Cancer Educ 2011, 2:186-192.

17. Nishino T, Katayama K, Takahashi Y, Tanaka T: A case of primary malignant lymphoma of the breast combined with ductal carcinoma in situ in the same gland lobules. J Jpn Surg Assoc 2011, 72:1952-1958.

18. Susnik B, Rowe JJ, Redlich PN, Chitambar C, Chang CC, Kampalath B: $A$ unique collision tumor in breast. Invasive ductal carcinoma and mucosa-associated lymphoid tissue lymphoma. Arch Pathol Lab Med 2004, 128:99-101

19. Anavekar NS, Rozen WM, Rowe K, Murphy C: Synchronous carcinoma and lymphoma of the breast. Clin Breast Cancer 2008, 8:281-284.

20. Holland JF, Pogo BG: Mouse mammary tumor virus-like viral infection and human breast cancer. Clin Cancer Res 2004, 10:5647-5649.

21. Salmons B, Gunzburg WH: Revisiting a role for mammary tumor retrovirus in human breast cancer. Int J Cancer 2013, 133:1530-1535.

22. Ohtsubo K, Sata M, Kawaguchi T, Morishige S, Takata Y, Oku E, Imamura R, Seki R, Hashiguchi M, Osaki K, Yakushiji K, Kanaji T, Yoshimoto K, Ueno T, Okamura T: Characterization of the light chain-restricted clonal B cells in peripheral blood of HCV-positive patients. Int J Hematol 2009, 89:452-459.

23. Viswanatha DS, Dogan A: Hepatitis C virus and lymphoma. J Clin Pathol 2007, 60:1378-1383

24. Okan V, Yilmaz V, Bayram A, Kis C, Cifci S, Buyukhatipoglu H, Pehlivan M: Prevalence of hepatitis $B$ and $C$ viruses in patients with lymphoproliferative disorders. Int J Hematol 2008, 88:403-408.
25. Wong WW, Schild SE, Halyard MY, Schomberg PJ: Primary non-Hodgkin lymphoma of the breast: the mayo clinic experience. J Surg Oncol 2002, 80:19-25.

26. Broco S, Bonito N, Jacinto P, Sousa G, Gervasio H: Primary non-Hodgkin lymphoma and invasive ductal carcinoma in the same breast: a rare case report. Clin Trans Oncol 2009, 11:186-188.

doi:10.1186/1477-7819-12-286

Cite this article as: Nishikawa et al:: Synchronous ipsilateral carcinoma of the accessory mammary gland and primary lymphoma of the breast with subsequent rectal carcinoma: report of a case. World Journal of Surgical Oncology 2014 12:286.

\section{Submit your next manuscript to BioMed Central and take full advantage of:}

- Convenient online submission

- Thorough peer review

- No space constraints or color figure charges

- Immediate publication on acceptance

- Inclusion in PubMed, CAS, Scopus and Google Scholar

- Research which is freely available for redistribution

Submit your manuscript at www.biomedcentral.com/submit
C BioMed Central 